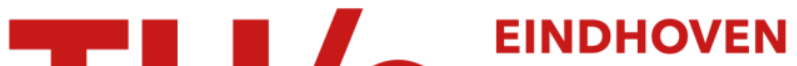 UNIVERSITY OF TECHNOLOGY
}

\section{Kinetics of organic compound removal from waste gases with a biological filter}

Citation for published version (APA):

Ottengraf, S. P. P., \& Oever, van den, A. H. C. (1983). Kinetics of organic compound removal from waste gases with a biological filter. Biotechnology and Bioengineering, 25(12), 3089-3102.

https://doi.org/10.1002/bit.260251222

DOI:

10.1002/bit.260251222

Document status and date:

Published: 01/01/1983

Document Version:

Publisher's PDF, also known as Version of Record (includes final page, issue and volume numbers)

Please check the document version of this publication:

- A submitted manuscript is the version of the article upon submission and before peer-review. There can be important differences between the submitted version and the official published version of record. People interested in the research are advised to contact the author for the final version of the publication, or visit the $\mathrm{DOI}$ to the publisher's website.

- The final author version and the galley proof are versions of the publication after peer review.

- The final published version features the final layout of the paper including the volume, issue and page numbers.

Link to publication

\section{General rights}

Copyright and moral rights for the publications made accessible in the public portal are retained by the authors and/or other copyright owners and it is a condition of accessing publications that users recognise and abide by the legal requirements associated with these rights.

- Users may download and print one copy of any publication from the public portal for the purpose of private study or research.

- You may not further distribute the material or use it for any profit-making activity or commercial gain

- You may freely distribute the URL identifying the publication in the public portal.

If the publication is distributed under the terms of Article $25 \mathrm{fa}$ of the Dutch Copyright Act, indicated by the "Taverne" license above, please follow below link for the End User Agreement:

www.tue.nl/taverne

Take down policy

If you believe that this document breaches copyright please contact us at:

openaccess@tue.nl

providing details and we will investigate your claim. 


\title{
Kinetics of Organic Compound Removal from Waste Gases with a Biological Filter
}

\author{
S. P. P. OTTENGRAF and A. H. C. VAN DEN OEVER, Department of \\ Chemical Engineering, Eindhoven University of Technology, Eindhoven, \\ The Netherlands
}

\begin{abstract}
Summary
In order to eliminate organic pollutants in waste gases, a biological filter bed technique has been developed, with a high self-regenerating capacity and a low pressure drop. The bed consists of an appropriate filling material (mainly peat compost), in order to let the microorganisms grow on the solid surface and to supply them with inorganic nutrients. Most organic compounds are oxidized to carbon dioxide and water. The compositions of the solid phase and the viable organisms present are such that aging is prevented, as a result of which a relatively high activity can be maintained during a long period of time (years). Experiments have been carried out in laboratory-scale columns with composite gas mixtures at varied concentrations and superficial gas velocities. The (macro) kinetics of the elimination processes have been studied, which enables the prediction of the elimination capacity of the filter bed.
\end{abstract}

\section{INTRODUCTION}

In process and bioindustry, wastewater and sewage treatment works, and some branches of the food and allied products industry, problems are often encountered, with respect to waste gases, in which odorous organic components are present. In many cases, this kind of air pollution is only a source of nuisance, although sometimes the presence of toxic substances-even in low concentrations-directly endangers health. In many countries, a statutory control of air pollution is enforced, as a result of which small factories and industries (e.g. chemical plants, color factories, lacqueries, etc.) are in want of simple, inexpensive, and reliable waste gas cleaning techniques. The common air deodorization processes applied are 1) physical treatment, such as absorbing or adsorbing polluting constituents in liquid or solid materials (e.g. activated carbon) or UV radiation and 2) chemical treatment, e.g., incineration, catalytic combustion, ozonization, and chlorination.

It is surprising that up to now little attention has been paid to the use of (micro)biological methods in the treatment of air effluents, although this technique can offer a number of advantages: it is inexpensive, reliable, and kind to the environment. In the case of biological treatment, waste gases are forced to rise through a packed bed, in which microorganisms are attached to an appropriate filling material, in order to let the microorganisms grow and 
to supply them with nutrients supplementary to those present in the waste gas.

Up to now, this method has mainly been applied to eliminate odorous compounds present in low concentrations in certain waste gases (e.g., wastewater treatment plants, stock farms, compost factories, etc.). Thistlethwayte and co-workers ${ }^{1}$ describe a trickling column packed with river gravel or with glass balls in which waste air, containing $\mathrm{H}_{2} \mathrm{~S}, \mathrm{C}_{2} \mathrm{H}_{5} \mathrm{SH},\left(\mathrm{C}_{2} \mathrm{H}_{5}\right)_{2} \mathrm{NH}$, and $\mathrm{C}_{4} \mathrm{H}_{9} \mathrm{CHO}$ flows in countercurrent with a nutrition solution. The column was seeded with activated sludge from sewage treatment works. Dependent on the liquid and air flow rate to the column, the removal percentages observed were from 40 up to $100 \%$ for the various contaminants. In German patent 2445.315 (Cl.B01D), Kneer ${ }^{2}$ describes a method, in which organic impurities of waste gas or air are adsorbed by forcing the gas to rise through a bed containing particles inoculated with a biologically active material. The adsorbent particles are continuously removed at the bottom and after regeneration returned to the top of the container. Helmer ${ }^{3}$ uses soil filter beds to extract products of anaerobic fermentation of organic materials (e.g., $\mathrm{NH}_{3}, \mathrm{H}_{2} \mathrm{~S}$, sulfides, alcohols, and aldehydes). Various types of filter beds, dry and wet, are described. Regeneration processes of the filter bed by microbial, thermal, and chemical methods are discussed by the author.

In our laboratory, an experimental investigation has been carried out to achieve the biological elimination of organic compounds from air effluents of lacqueries in a self-regenerating filter bed. We believe this technique is very promising for the treatment of many kinds of waste gases containing volatile organic compounds.

\section{EXPERIMENTAL SETUP}

Experiments on the laboratory as well as the pilot scale have been carried out at room temperature during a period of almost two years. A scheme of the laboratory scaled experimental setup is shown in Figure 1. The laboratoryscale apparatus consists of Quick fit glass columns divided into five separate stages with an inner diameter of 6 in., having a height of $60 \mathrm{~cm}$ each.

At the bottom of each stage a perforated sieve plate is fitted to support the package, which consists mainly of peat compost. The package is inoculated with an activated sludge suspension from a municipal wastewater treatment plant and with a toluene-eliminating organism, isolated from samples of soil, taken in the vicinity of a petrol-filling station. To keep the humidity of the filter bed at a desired level of ca. $50-70 \%$, tap water is periodically sprayed by a nozzle, mounted at the top of each stage. Humidification of the package can also be carried out in a separate wetting column outside the filter bed. There is generally no other water removal from the system other than by the watersaturated effluent gas.

Experimentally, it has proved to be important to fulfill humidification conditions as best as possible. At an insufficient supply of water, the bed dries up 

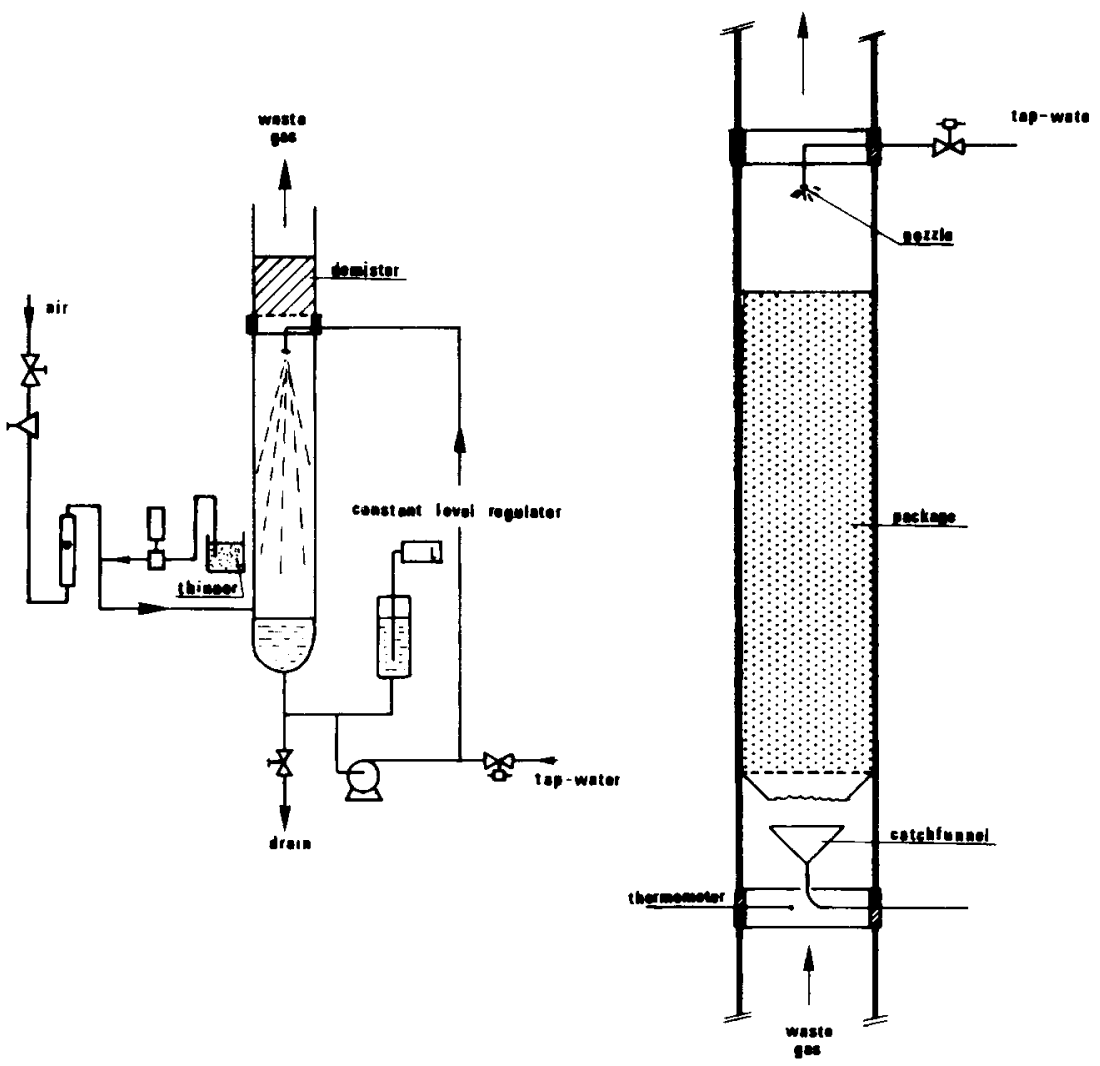

Fig. 1. Experimental setup of the biological filter bed.

at the gas inlet side and loses its activity, while an excess of water promotes the development of anaerobic zones in the bed. Foul smelling volatile metabolic products are disengaged in these zones and transported by the gas flow.

An organic liquid phase (thinner) is continuously dosed by an Ismatic plunger pump and evaporated by injecting it in the influent air stream. The composition of the thinner, which is frequently applied in lacqueries, is: ethylacetate $(157 \mathrm{~g} / \mathrm{L})$, toluene $(460 \mathrm{~g} / \mathrm{L})$, butylacetate $(121 \mathrm{~g} / \mathrm{L})$, and butanol $(56 \mathrm{~g} / \mathrm{L})$. No other nutrients, organic nor inorganic, are supplied to the filter bed.

In the experiments, the load of the column was varied, by varying either the superficial gas velocity (from \pm 1 to $\pm 15 \mathrm{~cm} / \mathrm{s}$ ) or the concentration of the constituent organic components in the artificial waste gas. In Table I, the composition of the waste gas is shown at a low and a high superficial gas velocity.

The analysis of gas phase samples was performed with the aid of a gas chromatograph, using a column packed with $30 \%$ polyglycol on gaschrom $80-100$ mesh, and an FID as a detector. 
TABLE I

Gas Inlet Concentrations

\begin{tabular}{lcc}
\hline & \multicolumn{2}{c}{$\begin{array}{c}\text { Gas velocity } \\
(\mathrm{cm} / \mathrm{s})\end{array}$} \\
\cline { 2 - 3 } Component & 0.84 & 14.8 \\
\hline & \multicolumn{2}{c}{ Gas inlet concentration } \\
& \multicolumn{2}{c}{$\left(\mathrm{g} / \mathrm{m}^{3}\right)$} \\
\hline Toluene & 5.606 & 0.308 \\
Butylacetate & 1.527 & 0.050 \\
Ethylacetate & 1.377 & 0.064 \\
Butanol & 0.692 & $\cdots$ \\
\hline
\end{tabular}

\section{THEORETICAL MODEL}

In the following, a theoretical model is presented which describes the elimination of the carbon sources in the filter bed. This model builds on a theoretical model that was already presented by Jennings and co-workers ${ }^{4}$ and which was commented by Ottengraf. ${ }^{5}$ Jennings developed a mathematical model for percentage of removal of a pure, nonadsorbable, biodegradable substrate in a submerged biological filter using the nonlinear Monod expression for the substrate utilization rate. In their model, the authors start from a biological slime layer coating a spherical particle. The slime layer is in its turn surrounded by a liquid boundary layer. In the liquid boundary layer, Jennings and co-workers properly suppose interface mass transfer resistance.

However, in the case of gas-phase filter beds, the number of mass-transfer units are generally much higher than in liquid-phase filter beds. This means that interface resistance in the gas phase can generally be neglected and therefore the biolayer concentration at the interface may be assumed to be in equilibrium with the concentration of the bulk gas (Fig. 2).

Moreover the following assumptions are made in the present model:

1) In the biolayer nutrients, are transported by diffusion, which is described by an effective diffusion coefficient $D^{\prime}$.

2) The biolayer thickness $\delta$ is small compared to the diameter of the coated particles (peat compost).

3) The microkinetics of the substrate elimination reactions in the biolayer are of zeroth order in the nutrient concentration (this assumes a very low value of the Michaelis-Menten constant in the Monod equation). That zeroth-order kinetics can very well be encountered experimentally in such systems, will be covered later.

4) The flow of the gas phase through the filter bed is of the plug flow type. With these assumptions, the differential equation describing the concentration of a nutrient component $C_{l}$ inside the biolayer is: 


$$
D^{\prime} \frac{d^{2} C_{l}}{d x^{2}}-k=0
$$

where $k$ is a zeroth-order reaction rate constant.

With the boundary conditions:

$$
\begin{array}{ll}
x=0, & C_{l}=\frac{C_{g}}{m} \\
x=\delta, & \frac{d C_{l}}{d x}=0
\end{array}
$$

the solution becomes:

$$
\frac{C_{l}}{C_{g} / m}=1+\frac{1}{2} \frac{\phi^{2}}{C_{g} / C_{g o}}\left(\sigma^{2}-2 \sigma\right)
$$

where

$$
\phi=\sqrt{\frac{k m}{D^{\prime} C_{g o}}}
$$

is the Thiele number; $\sigma=x / \delta$ is the dimensionless length coordinate in the biolayer; and $m=\left(C_{g} / C_{l}\right)_{\text {equilibrium }}$ is the distribution coefficient.

We now must distinguish between two situations ${ }^{5}$ :

1) There is no diffusion limitation in the wet biolayer. This means that the biolayer is fully active and hence the conversion rate is only controlled by the reaction rate. This situation will be defined as reaction limitation.

2) Diffusion limitation occurs in the wet biolayer. This means that the biolayer is not fully active or in other words the depth of penetration in the biolayer is smaller than the layer thickness $\delta$. In this case, the conversion rate will be controlled by the rate of diffusion. This situation will be referred to as diffusion limitation.

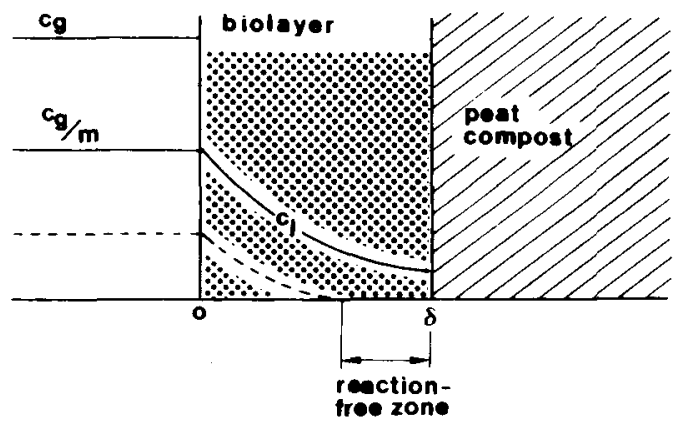

Fig. 2. The biophysical model for the biological filter bed. 


\section{Reaction Limitation}

From a gas-phase mass balance on the substrate it follows for the gas concentration at a height $h$ of the filter bed, with $A_{s}$ the biolayer surface per volume of package and $N$ the substrate flux into the biolayer:

$$
-U_{g} \frac{d C_{g}}{d h}=N A_{s}
$$

where

$$
N=\frac{-D^{\prime}}{\delta}\left(\frac{d C_{l}}{d \sigma}\right)_{\sigma=0}=k \delta
$$

From eqs. (5) and (6) it follows for the exit gas concentration $C_{g e}$ with the boundary conditions $h=0$ and $C_{g}=C_{g o}$ :

$$
\frac{C_{g e}}{C_{g o}}=1-\frac{A_{s} k \delta H}{C_{g o} U_{g}}
$$

where $H$ is the height of the tower. Assuming $A_{s} k \delta=K$ to be constant, it follows that

$$
\frac{C_{g e}}{C_{g o}}=1-\frac{K H}{C_{g o} U_{g}}
$$

and for the degree of conversion $f$ :

$$
f=1-\frac{C_{g e}}{C_{g o}}=\frac{K H}{C_{g o} U_{g}}
$$

\section{Diffusion Limitation}

This phenomenon, which is schematically shown in Figure 2 by the dotted line, occurs at an insufficiently high rate of diffusion compared to the substrate utilization rate. As the rate of diffusion is controlled by the concentration gradient in the biolayer and therefore by the concentration level at the interface, this situation is possible at lower gas-phase concentration levels. The occurrence of a reaction-free zone is physically determined by the value of the Thiele number. By substituting $C_{l}=0$ at $\sigma=1$ in eq. (4), it can easily be derived that the critical value of the Thiele number at which diffusion limitation just occurs amounts to:

$$
\phi_{\mathrm{cr}}=\delta \sqrt{\frac{k m}{D^{\prime} C_{g}}}=\sqrt{2}
$$

At lower gas-phase concentrations, $C_{g}$ corresponding with this value, the conversion rate and thus the elimination capacity of the filter bed will not only be controlled by the reaction rate but also by the diffusion rate in the biolayer. That this condition is indeed experimentally encountered will be shown in the next section. 
The boundary condition according to eq. (3) has now changed into:

$$
x=\lambda, \quad \frac{d C_{l}}{d x}=0
$$

The solution of differential eq. (1) becomes:

$$
\frac{C_{l}}{C_{g} / m}=1+\frac{1}{2} \frac{\phi^{2}}{C_{g} / C_{g o}}\left(\sigma^{2}-2 \sigma \frac{\lambda}{\delta}\right)
$$

Since $C_{l}=0$ at $\sigma=\lambda / \delta$, eq. (10) makes it possible to calculate the penetration thickness $\lambda$ :

$$
\lambda=\sqrt{2 \frac{D^{\prime} C_{g}}{k m}}
$$

From a gas-phase mass balance on the substrate, it now follows for the gas concentration at a height $h$ of the filter bed:

$$
-U_{g} \frac{d C_{g}}{d h}=N A_{s}=k \lambda A_{s}
$$

From eqs. (11) and (12), it follows for the exit gas concentration $C_{g e}$ with the boundary conditions $h=0$ and $C_{g}=C_{g o}$ :

$$
\frac{C_{g e}}{C_{g o}}=\left(1-\frac{A_{s} H}{U_{g}} \sqrt{\frac{k D^{\prime}}{2 C_{g o} m}}\right)
$$

From eq. (13), it can be concluded that in this case the elimination capacity of the filter bed will be controlled by both the reaction rate as well as the diffusion rate.

\section{EXPERIMENTAL RESULTS}

\section{Batch-Experimental Investigation of the Microkinetics}

From experimental studies in shaking flasks, the microkinetics of the substrate elimination reactions have been determined. For that purpose, a sample of the soil in the filter column was taken, and from it three strains were isolated. Each of these strains was inoculated in four shake flasks, containing either butanol, butylacetate, ethylacetate, or toluene as a sole carbon source in a watery solution of inorganic nutrients. The composition of the inorganic nutrient base is given in Table II. The concentrations of the carbon sources in these cultures were measured as a function of time.

As an example, Figure 3 shows the measured concentrations of toluene as a carbon source. From the experimental data, a value of the maximum growth rate of $\mu_{\max }=0.60 \mathrm{day}^{-1}$ has been calculated by means of a LineweaverBurk plot. As is shown in the figure, there is a good agreement with the theoretical path according to zeroth-order reaction kinetics. 
TABLE II

Composition of the Nutrient Solution

\begin{tabular}{lrcc}
\hline \multicolumn{1}{c}{ Component } & $\begin{array}{c}\text { Amount } \\
(\mathrm{mg} / \mathrm{L})\end{array}$ & Component & $\begin{array}{c}\text { Amount } \\
(\mathrm{mg} / \mathrm{L})\end{array}$ \\
\hline$\left(\mathrm{NH}_{4}\right)_{2} \mathrm{SO}_{4}$ & 1000 & $\mathrm{~K}_{2} \mathrm{HPO}_{4}$ & 84 \\
$\mathrm{MgSO}_{4} \cdot 7 \mathrm{H}_{2} \mathrm{O}$ & 42 & $\mathrm{CaCl}_{2} \cdot 2 \mathrm{H}_{2} \mathrm{O}$ & 42 \\
$\mathrm{KH}_{2} \mathrm{PO}_{4}$ & 42 & $\mathrm{FeCl}_{3}$ & 0,8 \\
\hline
\end{tabular}

From the batch experimental investigations, it has been concluded that all the carbon sources investigated are eliminated according to a zeroth-order reaction, down to very low concentrations of the carbon source. The calculated values of the maximum growth rate $\mu_{\max }$ are listed in Table III.

\section{Experimental Results from a Continuously Operating Filter Column}

After filling the column with peat compost, inoculated with suitable microorganisms, the filter takes about ten days to reach steady-state conditions. The substrate elimination was determined by taking gas-phase samples at the top of each stage in the column, and measuring the concentrations of the four carbon sources. As an example, some measured concentrations are plotted as a function of the height in the column in Figure 4.

It can be concluded that the elimination of the four carbon sources occurs according to a zeroth-order reaction. The concentration profiles show a linear dependence to the height according to eq. (7). However, the ratios of the calculated reaction rates do not agree with those determined in the batch experiments. This is probably due to the fact that the latter experiments were car-

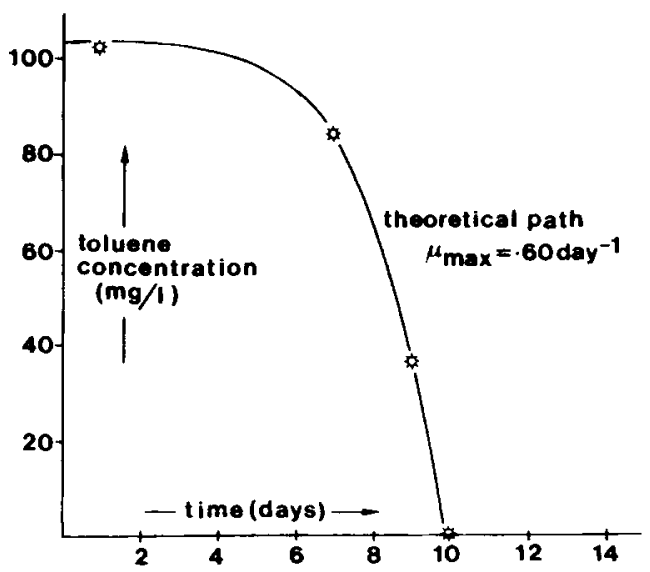

Fig. 3. Experimental determination of the microkinetics for the toluene elimination. (The drawn line is the theoretical zeroth-order reaction curve.) 
TABLE III

Maximum Growth Rate $\left(\mu_{\max }\right)$

\begin{tabular}{lc}
\hline Carbon source & $\begin{array}{c}\mu_{\max } \\
\left(\text { day }^{-1}\right)\end{array}$ \\
\hline Toluene & 0.60 \\
Butanol & 1.66 \\
Ethylacetate & 1.74 \\
Butylacetate & 2.35 \\
\hline
\end{tabular}

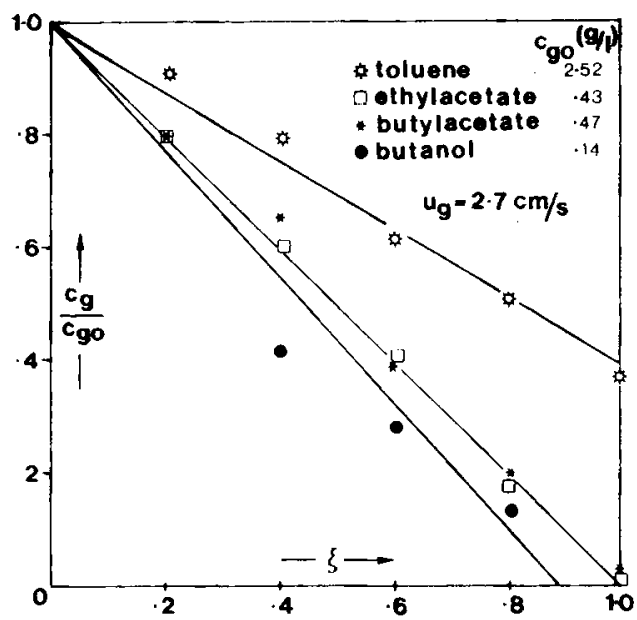

Fig. 4. Gas concentration profiles in the filter bed at different values of the degree of converion for a zeroth-order reaction.

ried out with single carbon sources, and the continuous experiments with a mixture of them.

As has been pointed out in the Theoretical Model section, the elimination capacity of the filter bed will no longer be constant, but decreases below a critical value of the gas-phase concentration. This phenomenon, which is due to diffusion limitation in the biolayer, is clearly shown in Figure 5. For the components butylacetate, ethylacetate, and toluene, the elimination capacity is plotted as a function of the influent gas concentration at a constant load to the filter bed. The critical gas-phase concentrations amount to ca. $0.2 \mathrm{~g} / \mathrm{L}$ for butylacetate and ethylacetate and about $3 \mathrm{~g} / \mathrm{L}$ for toluene. These values allow to estimate from eq. (9) the biolayer thickness $\delta$. It should be kept in mind that in eq. (9) $k$ represents the reaction rate per unit of volume of the biolayer, while the elimination capacity $k^{*}$, shown in Figure 5 , is expressed per unit of volume of the filter package. It can easily be derived that the relation between these two magnitudes is given according to: 


$$
k=k^{*} \frac{1}{(1-\epsilon)\left[1-\left(1-\frac{2 \delta}{d_{p}}\right)^{3}\right]}
$$

where $\epsilon$ is the void fraction of the package and $d_{p}$ is the mean particle diameter.

The values of $\epsilon$ (being \pm 0.29 ) and $d_{p}$ (being $\pm 8.5 \times 10^{-3} \mathrm{~m}$ ) can be estimated from the pressure drop in the filter bed by means of the Ergun relation. In Table IV, the calculated values for the biolayer thickness are given; they look very reasonable.

The phenomenon of diffusion limitation in the biolayer also finds its expression, if the gas-phase concentration is plotted as a function of the height in the column at low inlet gas concentrations (Fig. 6). If the rate of conversion is controlled by the diffusion rate in the biolayer, this profile is no longer lin-

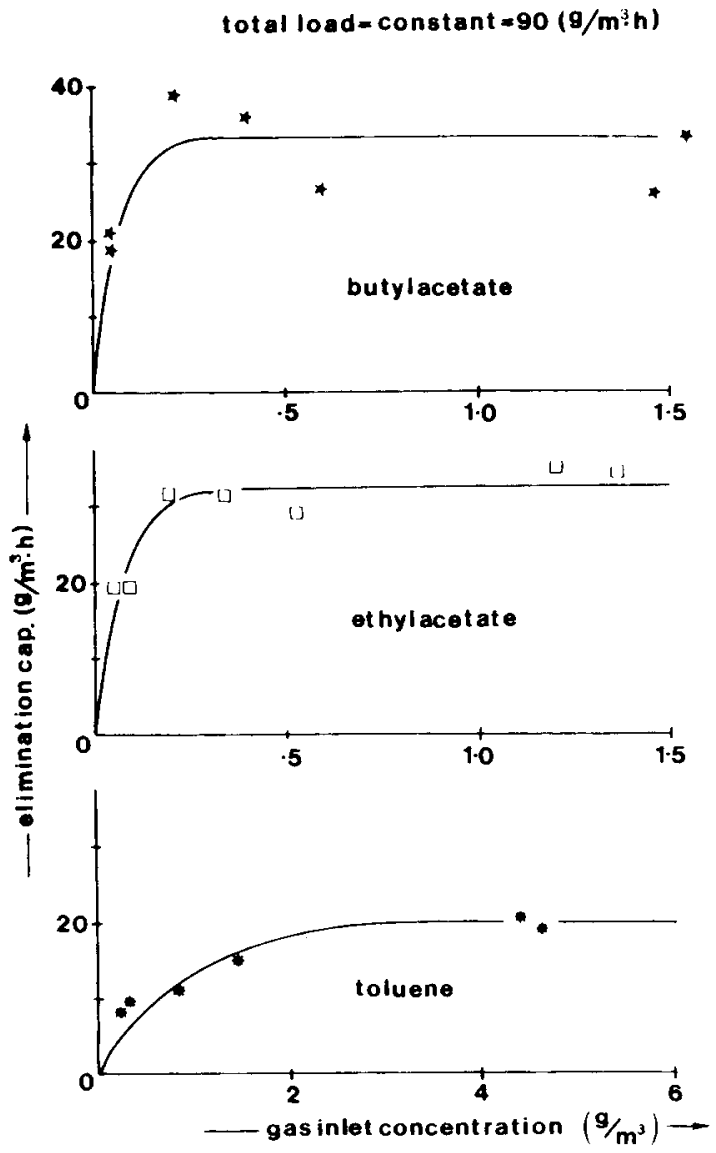

Fig. 5. The elimination capacity versus the influent gas concentration at constant load. 
TABLE IV

Biolayer Thickness $(\delta)$

\begin{tabular}{lcccccc}
\hline \multicolumn{1}{c}{ Component } & $m$ & $\begin{array}{c}k^{*} \\
\left(\mathrm{~g} / \mathrm{m}^{3} \mathrm{~h}\right)\end{array}$ & $\begin{array}{c}k \\
\left(\mathrm{~g} / \mathrm{m}^{3} \mathrm{~h}\right)\end{array}$ & $\begin{array}{c}D^{\prime} \\
\left(\mathrm{m}^{2} / \mathrm{s}\right)\end{array}$ & $\begin{array}{c}C_{\mathrm{gcr}} \\
\left(\mathrm{g} / \mathrm{m}^{3}\right)\end{array}$ & $\begin{array}{c}\delta \\
(\mathrm{mm})\end{array}$ \\
\hline Toluene & 0.2700 & 20 & 50 & $0.85 \times 10^{-9}$ & 3.0 & 1.2 \\
Butylacetate & 0.0085 & 30 & 55 & $0.80 \times 10^{-9}$ & 0.2 & 1.5 \\
Ethylacetate & 0.0051 & 30 & 45 & $1.0 \times 10^{-9}$ & 0.2 & 2.5 \\
\hline
\end{tabular}

ear but shows a dependency on the height according to eq. (14). The measured points are in good agreement with the expected theoretical curve.

The measured pressure drop in the biological filter bed as a function of the superficial gas velocity is shown in Figure 7. From the path of this curve and the Ergun relation-which gives the pressure drop in a packed bed-it can be concluded that kinetic energy losses must play an important role at the applied gas velocities and thus the pressure drop is not only due to friction.

After several months of operation, the elimination capacity of the filter bed showed a decrease. Analysis of the filter bed has shown that this phenomenon is probably due to a decrease of the $\mathrm{pH}$ value from ca. 7 to ca. 4 . The production of acid intermediates (e.g. acetic acid) from ethyl- and butylacetate is the cause of this $\mathrm{pH}$ drop, which decreases or can even stop the microbial activity. This has been verified by batch experiments in shake flasks. The addition of limestone or other water-insoluble alkalis to the filter packing has proved a working remedy against the occurrence of this phenomenon.

We used marl as an additive to the peat compost. To ensure a good operation during a long period of time (years) the applied concentration should amount to about 2 wt \%.

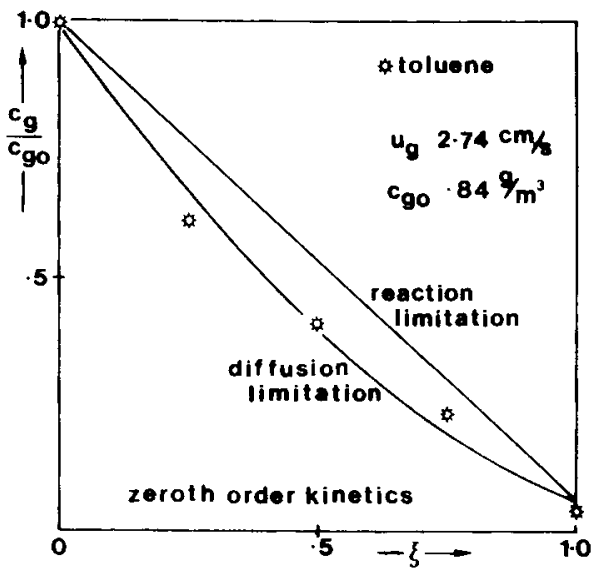

Fig. 6. The concentration as a function of the height in the column in the case of diffusion limitation in the biolayer. 


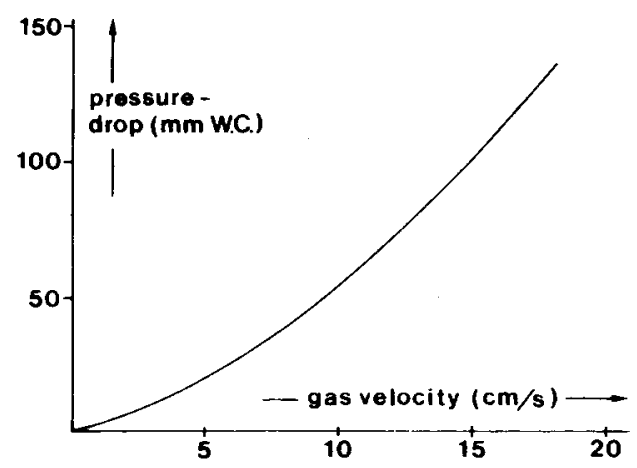

Fig. 7. The pressure drop in the filter bed as a function of the superficial gas velocity.

A summary of experimental data covering a period of about six months is given in Figure 8 . This figure shows the elimination capacity of the biological filter bed as a function of the load. Results are plotted for the first, third, and fifth stages. The elimination rates as well as the loads are per unit of volume of each stage. The results have been obtained at several superficial gas velocities, varying from ca. 1 to $14 \mathrm{~cm} / \mathrm{s}$.

It can be concluded that in the first stage all the organic components are simultaneously eliminated. The maximum elimination rate for each component in this stage amounts to ca. $20-40 \mathrm{~g} / \mathrm{m}^{3} \mathrm{~h}$. In this stage, butanol and ethylacetate are nearly completely eliminated at the applied loads. The upper part of the column mainly eliminates toluene which, in the inlet gas stream, is present in a much higher concentration than the other components. It is a little surprising that the maximum elimination rate for this singly present component is of about the same magnitude as found for toluene in the first stage. It may probably be concluded that in the filter bed different microbial populations are responsible for the elimination of the different organic components.

The microbial flora appears to survive a fairly long period during which the filter bed is not loaded. Experiments have shown that periods of a fortnight are easily spanned with hardly any loss of microbial activity. This is important in view of the dynamic behaviour of the filter bed at discontinuous operation, and means a very short starting time after longer periods of not operating the filter bed (e.g. holidays).

Summarizing, it may be concluded that the use of microbial filter bed techniques in the treatment of air effluents containing organic pollutants can offer a number of advantages. The use of this method, which is reliable, inexpensive, and kind to the environment, deserves more attention than it has received up to now.

The authors would like to express their thanks to Ir. H. Verhagen, Ir. J. M. Claessen, and Ir. I. Durlinger for their contributions during the last year of their course of engineering. 

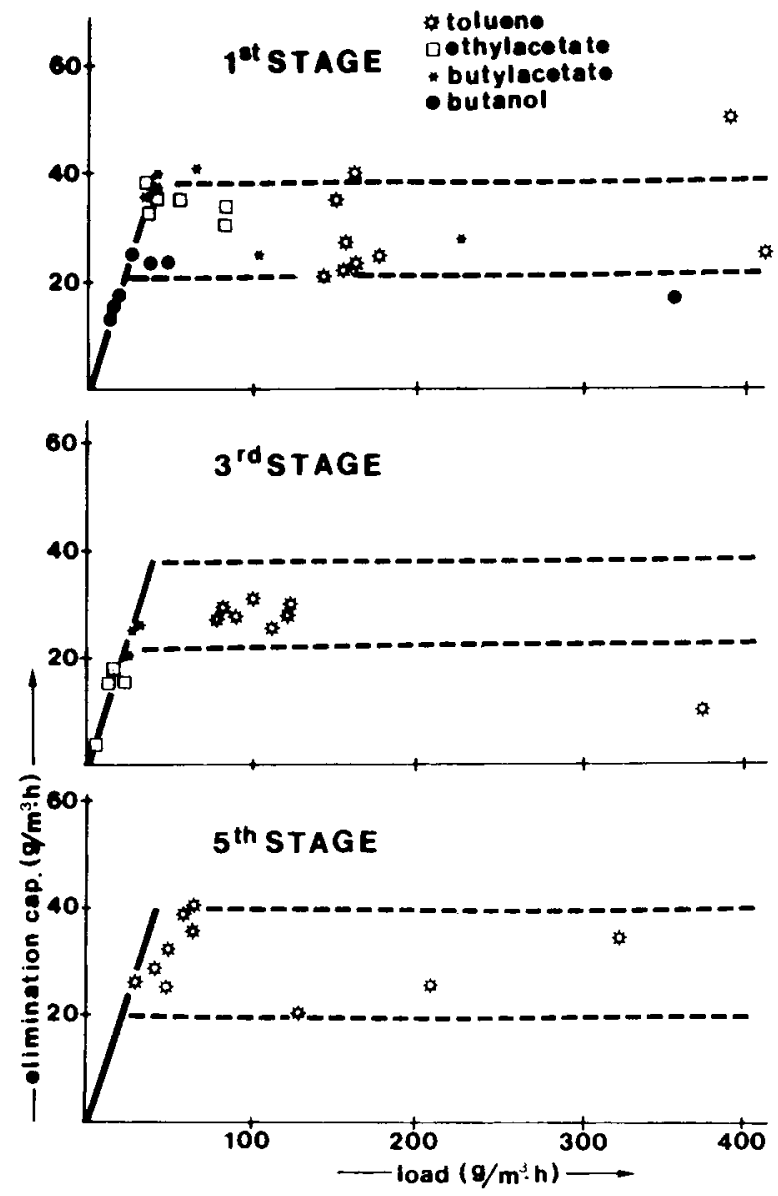

Fig. 8. The elimination capacity of the filter bed as a function of the load of the bed.

\section{Nomenclature}

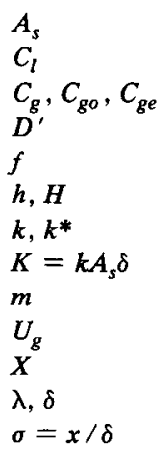

specific area $\left(\mathrm{m}^{2} / \mathrm{m}^{3}\right)$

liquid phase concentration $\left(\mathrm{g} / \mathrm{m}^{3}\right)$

gas phase concentration $\left(\mathrm{g} / \mathrm{m}^{3}\right)$

effective diffusion coefficient $\left(\mathrm{m}^{2} / \mathrm{s}\right)$

degree of conversion (dimensionless)

height $(\mathrm{m})$

zero-order reaction rate constant $\left(\mathrm{g} / \mathrm{m}^{3} \mathrm{~s}\right)$

reaction rate constant $\left(\mathrm{g} / \mathrm{m}^{3} \mathrm{~s}\right)$

distribution coefficient (dimensionless)

superficial gas velocity $(\mathrm{m} / \mathrm{s})$

length coordinate $(\mathrm{m})$

effective and total biolayer thickness $(\mathrm{m})$

dimensionless length coordinate (dimensionless) 


$$
\begin{array}{ll}
\phi=\delta \sqrt{\frac{k m}{D^{\prime} C_{g o}}} & \text { Thiele number (dimensionless) } \\
\xi=h / H & \text { dimensionless height (dimensionless) }
\end{array}
$$

\section{References}

1. D. K. B. Thistlethwayte, B. Hardwick, and E. E. Goleb, Chimie Ind., 106, 795 (1973).

2. F. Kneer, "Einrichtung zum Abscheiden gasförmiger organischer Veruntreinigungen aus Abgasen," German Patent No. 2.4.45 315 (Cl.BOID) (1976).

3. R. Helmer, Ges. Ing., 95, 21 (1974).

4. P. A. Jennings, V. L. Snoeyink, and E. S. K. Chian, Biotechnol. Bioeng., 23, 1249 (1976).

5. S. P. P. Ottengraf, Biotechnol. Bioeng., 19, 1411 (1977).

Accepted for Publication May 12, 1983 